\title{
Interconsequence generality of learned helplessness
}

\author{
MICHAEL D. MAUK and EDWARD J. PAVUR, JR. \\ University of New Orleans, New Orleans, Louisiana 70122
}

\begin{abstract}
The present study tested the interconsequence generality of the learned helplessness phenomenon. Thirty-six rats received escapable, inescapable, or no shock in a shuttlebox. Intact triads were then randomly assigned to two groups. The first group was required to learn to escape shock via barpressing; the second was required to learn a six-unit maze for food reward. The shock-escape triads demonstrated the standard learned helplessness effect, with inescapable subjects inferior to escapable and unshocked animals. However, the triads tested in the appetitive situation did not exhibit learned helplessness, but rather, they exhibited a trauma-like effect, with both escapable and inescapable subjects inferior to no-shock control subjects on early trials. These findings demonstrated a limit to the generality of learned helplessness. It was suggested that learned helplessness follows the rules of stimulus and response generalization.
\end{abstract}

Organisms exposed to inescapable shock in one situation often fail to learn to escape shock in a different situation (Seligman \& Maier, 1967). This phenomenon, known as "learned helplessness," is currently being researched and debated as a model for depression in humans. Of critical importance to the strength of this model is the generality of the helplessness phenomenon.

Several criteria must be met for the effects of learned helplessness to be considered general. First, the effects must be produced with a variety of organisms to demonstrate species generality. Second, effects must transfer across different tasks to demonstrate task generality. Third, the effects of noncontingent treatments relative to each type of instrumental learning consequence (positive reinforcement, negative reinforcement, and punishment by application and removal) must be produced to demonstrate intraconsequence generality. Finally, at the highest level of generality, effects relative to any instrumental consequence must transfer to any other consequence to demonstrate interconsequence generality.

Available evidence certainly satisfies the criteria of species and task generality. Learned helplessness effects have been produced in a variety of organisms, including dogs, cats, pigeons, and rats, using a wide range of tasks, such as barpressing, shuttling, and jumping (see Maier \& Seligman, 1976, for a review).

Evidence of intraconsequence generality is limited thus far to the two reinforcement consequences. Effects relative to negative reinforcement have been amply demonstrated, as the majority of learned helplessness research deals with shock escape. Rosellini and Seligman (1978) demonstrated effects across different levels of shock intensities, although paradigms incorporating identical shock intensities showed maximal effects. Negative reinforcement effects have also been demon- strated with aversive events other than electric shock. For example, Rosellini and Seligman (1975) found that inescapably shocked rats failed to learn a hurdle-jump escape from a frustrating goalbox, whereas escapably shocked and unshocked control rats did escape. Thus, learned helplessness produced with one aversive stimulus (shock) produced effects in a different aversive context (frustration). Welker (1976) demonstrated learned helplessness effects in an appetitive (positive reinforcement) situation. Acquisition of a treadle-pressing response for grain was retarded in pigeons previously exposed to response-independent food. More recently, similar effects were demonstrated with rats (Wheatly, Welker, \& Miles, 1977).

The present research was designed to determine whether learned helplessness produced in a standard aversive situation would interfere with learning in an appetitive situation. The treatment consisted of responsecontingent shock termination, noncontingent shock, or no shock experience in a shuttlebox. The test phase consisted of food reward contingent upon the completion of a six-unit maze.

Evidence that learned helplessness effects exhibit interconsequence generality has been reported. Goodkin (1976) reported that effects generalize from an appetitive situation to an aversive situation. Similarly, Wight and Katzev (1977) found noncontingent positive reinforcers retarded later escape/avoidance learning in rats. Thus, strong evidence exists that learned helplessness effects transfer from a positive reinforcement situation to a negative reinforcement situation. Recent evidence shows the converse is true as well. Rosellini (1978) reported that inescapable shock interfered with later acquisition of an appetitive barpress response. Only a slight interference was obtained when each barpress was immediately reinforced by food. More profound interference was 
found when a response-reinforcement delay of $1 \mathrm{sec}$ was imposed. Rosellini suggested that this finding was in agreement with aversive tests reported by Maier, Albin, and Testa (1973), in which the complexity of the escape response was found to be critical for the demonstration of learned helplessness effects.

The present study was aimed at testing the transfer of learned helplessness effects from an aversive situation to an appetitive maze-learning paradigm. If learned helplessness does exhibit interconsequence generality in a maze-learning paradigm, then one would expect results similar to those reported by Rosellini (1978). That is, inescapable shock would be expected to interfere with maze performance in early trials, as in the Rosellini (1978) study.

One study relating noncontingent shock to appetitive learning reported that noncontingent shock increased speed and reduced retracing during appetitive runway acquisition, relative to unshocked control animals (Chen \& Amsel, 1977, Experiment 1). However, that study differed from most learned helplessness studies in two respects: namely, the lack of a contingent shock group and the use of a simple task in the test phaserunning in a straight alley. Maier et al. (1973) have shown that, with rats as subjects, learned helplessness may be demonstrated with relatively complex tasks but not with simple tasks. This consideration led to the use of a complex task in the present study.

\section{METHOD}

\section{Subjects}

Subjects were 36 female Sprague-Dawley rats. They were 90 days old at the start of the experiment. The average ad-lib weight of the rats was $210 \mathrm{~g}$. All were maintained throughout the experiment at $80 \%$ of their ad-lib weights. Each was randomly assigned to the escapable, inescapable, or no-shock treatment group.

\section{Apparatus}

The shuttlebox was a $30 \times 30 \mathrm{~cm}$ grid shock box, fully partitioned into two $15 \times 30 \mathrm{~cm}$ cages. Each cage had a 4-cm high barrier capped with two shock bars to prevent rats from balancing on the barrier to avoid shock. The no-shock group was placed in an adjoining cage. A 1-mA shock was delivered by a BRS Foringer SG-901 generator and a SC-901 scrambler.

The barpress cage was a Scientific Prototype 106 D 700 cage with bar and scrambled 1-mA floor shock from the same source described above.

The maze consisted of a straight-runway startbox, six T-type choice points, and a goalbox. All parts were constructed with plywood, painted with light brown interior paint, and covered with clear plastic. The interior measurements of all parts of the maze were $9 \mathrm{~cm}$ wide $\times 13 \mathrm{~cm}$ high. The startbox was $55 \mathrm{~cm}$ long, with a sliding door $15 \mathrm{~cm}$ from the end to form the chamber into which the rats were initially placed. The decision points were $T$ mazes, modified so that the rats had no visual cues to the correct turn. There was a sliding door behind each decision point that was closed to prevent retracing. The goalbox was $25 \mathrm{~cm}$ square and contained five $45-\mathrm{g}$ Noyes food pellets.

\section{Procedure}

Each rat was exposed to 70 trials of escapable shock, yoked inescapable shock, or no shock experience in a shuttlebox. Shock was terminated when the escapable rat performed one shuttle response. If 10 consecutive responses were made in less than $2 \mathrm{sec}$, the requirement was raised to 2 shuttle responses. The average intertrial interval was $60 \mathrm{sec}$, ranging from 10 to $110 \mathrm{sec}$.

Four randomly selected triads (a triad consisted of an escapably shocked rat, its yoked partner, and a no-shock control rat) were assigned to barpress testing, and eight triads were assigned to maze testing. Both test phases began $24 \mathrm{~h}$ after treatment.

The barpress test phase consisted of 40 trials of shock, escapable by a single barpress. After $10 \mathrm{sec}$ the shock was terminated if no response had been made. The number of failures to escape was recorded.

The maze test phase consisted of six trials, two per day, distributed over 3 consecutive days. There was a minimum of $2.5 \mathrm{~h}$ between trials. Before each trial, the maze was cleaned with a $40 \%$ alcohol solution. Dependent variables were startbox latency (from the opening of the door to the complete leaving of the box), total time, and errors (defined as choosing the wrong turn or returning to an incorrect alley).

\section{RESULTS AND DISCUSSION}

The barpress data were analyzed by a simple analysis of variance. As expected, there was a reliable main effect due to treatment $[F(2,9)=23.70, p<.001]$. As in previous studies, the inescapable animals were more likely to fail to escape than the escapable and no-shock subjects. Respective mean failures to escape were 31.25 , 15.25 , and 14.25. Subsequent analyses with Scheffe's method of multiple comparisons showed the inescapable group to be significantly poorer $(p<.01)$ than the escapable and no-shock groups. However, the escapable and inescapable groups were not significantly different.

The maze data for startbox latency, total time, and errors were analyzed by separate 3 by 6 mixed analyses of variance. There were reliable effects due to trials for startbox latency $[F(5,105)=14.834, p<.001]$, total time $[F(5,105)=79.294, p<.001]$, and errors $[F(5,105)=4.44, p<.01]$. Additionally, there were reliable Treatment by Trials interactions for startbox latency $[F(10,105)=2.113, p<.05]$ and total time $[F(10,105)=2.286, p<.05]$, but not for errors $[F(10,105)<1]$. No other findings were significant.

Table 1 shows the Treatment by Trials interaction for total latency. The data for startbox latency paralleled the total latency data so closely that they will not be presented here. As can be seen in Table 1, both of the shock groups differed from the no-shock control group on the first three trials, but all three groups appeared

Table 1

Mean Total Time to Complete Maze (in Seconds)

\begin{tabular}{lccccccc}
\hline Condition & Trial 1 & Trial 2 & Trial 3 & Trial 4 & Trial 5 & Trial 6 & Combined \\
\hline Escapable & 283.0 & 110.5 & 103.8 & 71.9 & 65.0 & 47.4 & 113.6 \\
Inescapable & 261.6 & 106.4 & 87.6 & 63.5 & 65.5 & 51.9 & 106.1 \\
Control & 180.2 & 107.1 & 62.1 & 56.5 & 62.4 & 47.8 & 86.0 \\
\hline
\end{tabular}


to reach a plateau by Trial 4 . However, there was little difference between the escapable and inescapable subjects on any of the trials.

These results parallel the results obtained by Rosellini (1978) in that differences exist only in the early trials and all groups reach asymptote simultaneously. However, one major difference is evident. The maze data indicate that rats treated with inescapable or escapable shock are slower to start and complete a maze than are unshocked animals, but the absence of a difference between the two shock groups suggests that the effect is due to a generalized fear reaction produced by shock.

The present study demonstrated that an aversive treatment capable of producing learned helplessness effects in one aversive situation was unable to produce effects in a different, appetitive, maze-learning situation. Although helplessness effects as produced by a standard aversive treatment were not demonstrated under these particular positive reinforcement circumstances, these data are not necessarily in conflict with previous work. The present study attempted to demonstrate effects at what was regarded as an extremely high degree of generality, employing transfer from one learning consequence (escape) to another (reward), as well as using extremely dissimilar tasks (shuttlebox and maze) involving response learning and place learning.

It seems likely that learned helplessness follows the same rules of transfer that have been demonstrated for operant conditioning in general (Hulse, Deese, \& Egeth, 1975). That is, the more similar the situations, the greater the likelihood of transfer. Differences between a shuttlebox and maze may be too great to demonstrate transfer. Similarly, our learned helplessness treatment involved response learning, while our maze-learning test phase involved place learning. As Goodkin (1976) has suggested, learning relationships between responding and environmental events may not influence learning relationships between places and environmental events.
The emphasis of future research on generality should continue to parametrically explore the specific boundaries of learned helplessness transfer.

\section{REFERENCES}

Chen, J., \& Amsel, A. Prolonged, unsignaled, inescapable shocks increase persistence in subsequent appetitive instrumental learning. Animal Learning \& Behavior, 1977, 5, 377-385.

Goodkin, F. Rats learn the relationship between responding and environmental events: An expansion of the learned helplessness theory. Learning and Motivation, 1976, 7, 382-393.

Hulse, S. H., DeESE, J., \& EGETH, H. The psychology of learning (4th ed.). New York: McGraw-Hill, 1975.

Maier, S. F., Albin, R. W., \& Testa, T. J. Failure to learn to escape in rats previously exposed to inescapable shock depends on nature of escape response. Journal of Comparative and Physiological Psychology, 1973, 85, 581-592.

Maier, S. F., \& Seligman, M. E. P. Learned helplessness: Theory and evidence. Journal of Experimental Psychology: General, 1976, 105, 3-46.

Rosellini, R. A. Inescapable shock interferes with the acquisition of an appetitive operant. Animal Learning \& Behavior, 1978, 6, 155-159.

Rosellini, R. A., \& Seligman, M. E. P. Learned helplessness and escape from frustration. Journal of Experimental Psychology: Animal Behavior Processes, 1975, 1, 149-158.

Rosellini, R. A., \& Seligman, M. E. P. Role of shock intensity in the learned helplessness paradigm. Animal Learning \& Behavior, 1978, 6, 143-146.

Seligman, M. E. P., \& Maier, S. F. Failure to escape traumatic shock. Journal of Experimental Psychology, 1967, 74, 1-9.

WELKER, R. L. Acquisition of a free-operant-appetitive response in pigeons as a function of prior experience with responseindependent food. Learning and Motivation, 1976, 7, 394-405.

Wheatley, K. L., Welker, R. E., \& Miles, R. C. Acquisition of barpressing in rats following experience with responseindependent food. Animal Learning \& Behavior, 1977, 5, 236-242.

Wight, M. T., \& Katzev, R. D. Noncontingent positive reinforcers retard later escape/avoidance learning in rats. Bulletin of the Psychonomic Society, 1977, 9, 319-321.

(Received for publication September 21, 1979.) 